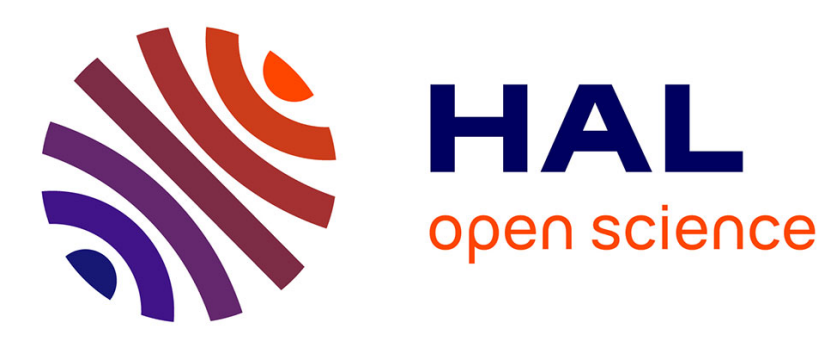

\title{
Patterns of Apis mellifera infestation by Nosema ceranae support the parasite hypothesis for the evolution of extreme polyandry in eusocial insects
}

A. Bourgeois, Thomas Rinderer, H. Sylvester, Beth Holloway, Benjamin

Oldroyd

\section{To cite this version:}

A. Bourgeois, Thomas Rinderer, H. Sylvester, Beth Holloway, Benjamin Oldroyd. Patterns of Apis mellifera infestation by Nosema ceranae support the parasite hypothesis for the evolution of extreme polyandry in eusocial insects. Apidologie, 2012, 43 (5), pp.539-548. 10.1007/s13592-012-0121-5 . hal-01003643

\section{HAL Id: hal-01003643 \\ https://hal.science/hal-01003643}

Submitted on 1 Jan 2012

HAL is a multi-disciplinary open access archive for the deposit and dissemination of scientific research documents, whether they are published or not. The documents may come from teaching and research institutions in France or abroad, or from public or private research centers.
L'archive ouverte pluridisciplinaire HAL, est destinée au dépôt et à la diffusion de documents scientifiques de niveau recherche, publiés ou non, émanant des établissements d'enseignement et de recherche français ou étrangers, des laboratoires publics ou privés. 


\title{
Patterns of Apis mellifera infestation by Nosema ceranae support the parasite hypothesis for the evolution of extreme polyandry in eusocial insects
}

\author{
A. Lelania Bourgeois ${ }^{1}$, Thomas E. Rinderer ${ }^{1}$, H. Allen Sylvester ${ }^{1}$, \\ Beth HollowaY ${ }^{1}$, Benjamin P. OldRoyd ${ }^{2}$ \\ ${ }^{1}$ USDA-ARS Honey Bee Breeding, Genetics, and Physiology Laboratory, 1157 Ben Hur Rd., Baton Rouge, \\ LA 70820, USA \\ ${ }^{2}$ Behaviour and Genetics of Social Insects Lab, School of Biological Sciences A12, University of Sydney, Sydney, \\ NSW 2006, Australia
}

Received 3 August 2011 - Revised 22 December 2011 - Accepted 16 January 2012

\begin{abstract}
We investigated the relationship between infestation levels of Nosema ceranae and patriline membership by sampling individual worker bees from five colonies from both Russian and Italian lineages. Individual workers were tested for $N$. ceranae infestation level using qPCR, and then genotyped to determine their patriline membership. Levels of $N$. ceranae infestation differed significantly between lineages and colonies for both Russian and Italian workers. Patriline-based variance was evident only among the Russian workers. There was substantial variation in $N$. ceranae levels among Italian workers, ranging from 0 to $2 \times 10^{9}$ Nosema/bee, but this variation was unrelated to patriline membership. The results for Russian honey bees are congruent with predictions derived from the parasite hypothesis for the evolution of polyandry-patrilinial variance in parasite tolerance contributes to colony level resistance by reducing the probability of catastrophic failure that might occur if a colony was genetically homogeneous.
\end{abstract}

polyandry / patriline / Nosema ceranae / Apis mellifera / evolution of polyandry

\section{INTRODUCTION}

Host-parasite relationships are inherently dynamic. The Red Queen hypothesis (van Valen 1973) predicts that host and parasite populations continually coevolve and tend to maintain their relative fitness. The framework of the hypothesis was expanded (Jaenike 1978; Hamilton 1980; Lively 1987; Hamilton et al. 1990; Lively et al. 1990; Ebert and Hamilton 1996) by proposing that sexual reproduction is an adaptation to resisting parasites since genetic recombination greatly increases the genetic variance

Corresponding author: A.L. Bourgeois, lanie.bourgeois@ars.usda.gov

Manuscript editor: Peter Rosenkranz for disease resistance in populations and accelerates the production of novel resistant phenotypes. An important feature of this hypothesis is that parasite-mediated selection pressures result in the maintenance of substantial genetic variance for resistance of a host population. The variance allows the host to evade the coevolving parasites and reflects the divergent selection pressures mediated by a parasite population that has genetic variance for virulence (Hamilton 1980; Hamilton et al. 1990; Ladie 1992).

In the honey bee (Apis mellifera L.) and other social insects, genetic variance exists both at the population level, as it does with other organisms, and also at the within-colony level. Within-colony variance has its origins in the extreme levels of polyandry (mating with $>10$ 
drones), which are a notable feature of honey bee biology (reviewed in Palmer and Oldroyd 2000). Selection for increased intracolonial disease resistance is a compelling hypothesis for the origin of polyandry (Tooby 1982; Hamilton 1987; Sherman et al. 1988; Shykoff and Schmid-Hempel 1991a, b; Schmid-Hempel 1995; but see van Baalen and Beekman 2006), just as increased variance in intrapopulational disease resistance is offered in the expanded "Red Queen" hypothesis for the evolutionary maintenance of sexual reproduction. This is supported by experimental evidence that shows a reduction in genetic variance within a colony increases disease severity (Tarpy 2003; Tarpy and Seeley 2006; Seeley and Tarpy 2007).

The microsporidian Nosema ceranae (Fries 2010) is an excellent pathogen with which to test the pathogen hypothesis for polyandry. This species expanded its host range from Apis cerana to Apis mellifera in the late 1980 s to early 1990 s and has now displaced Nosema apis (the naturally occurring microsporidian infecting A. mellifera) as the dominant microsporidian parasite of honey bees in the USA (Chen et al. 2008). Symptoms of $N$. ceranae infestations are less overt than those associated with $N$. apis infestations and consist primarily of poor colony growth and dwindling (Higes et al. 2008). However, current $N$. ceranae strains in the USA are more virulent than endemic N. apis (Higes et al. 2007; Paxton et al. 2007). Time course studies reveal that $N$. ceranae can cause substantial colony mortality (MartinHernandez et al. 2007; Higes et al. 2008). A parsimonious explanation for this elevated virulence is that most honey bee lineages are naive to the newly emerged parasite and have yet to evolve $N$. ceranae-specific genetic resistance.

In order to test if genetic resistance to $N$. ceranae exists among honey bees, we compared pathogen levels among patrilines within ten honey bee colonies, five of the Russian lineage and five of the Italian lineage. We predicted that polyandry in honey bee colonies would confer variation in resistance to $N$. ceranae. More specifically, we predicted that we would find significant variation in levels of $N$. ceranae among patrilines within individual honey bee colonies.

\section{MATERIALS AND METHODS}

\subsection{Sample collection-colony prescreening (phase 1)}

A total of 29 colonies of Russian honey bees and 22 Italian honey bee colonies from adjacent apiaries were chosen at random and sampled in April and June 2010 (respectively). Each colony was tested for the presence and extent of $N$. ceranae infestation following the protocols described below. We collected a scoop of foraging workers (approximately 150 workers) from the entrance and top bars of each colony. Workers were placed in a plastic bag on ice and transported back to the laboratory, at which time they were frozen and held at $-20^{\circ} \mathrm{C}$ until processing.

\subsection{Patriline sampling (phase 2)}

In May 2010, the five Russian colonies with the highest infestation levels of $N$. ceranae were chosen and sampled for $N$. ceranae and patriline analyses. In August 2010, the five Italian colonies with the highest infestation levels of $N$. ceranae were chosen and sampled for the same analyses. We chose those colonies with the highest infestation levels to increase the likelihood of obtaining individual bees with high $N$. ceranae levels. Approximately 200 foraging workers from each of the ten colonies (five Russian, five Italian) were sampled from both the entrance and top bars of each hive to ensure that only older bees were collected. Workers were placed in a plastic bag on ice and transported to the laboratory, where they were frozen and held at $-20^{\circ} \mathrm{C}$ until processing.

\subsection{DNA extraction}

Bees were prepared for DNA extraction by separation of the thorax and the abdomen. Each portion of an individual bee (144 workers per colony) was placed in a separate microfuge tube for DNA extraction. Two separate protocols (Bourgeois et al. 2010a, b) were used for DNA extraction for patriline determination and N. ceranae detection and quantification. Briefly these are: 


\subsubsection{Patriline determination}

DNA was extracted from the thorax of individual worker bees. Samples were first homogenized in lysis buffer (100 mM Tris pH 8.0, 10 mM EDTA pH 8.0, $1 \% \mathrm{SDS}$ ) with $100 \mathrm{mg} 1-\mathrm{mm}$ glass beads for $3 \mathrm{~min}$ at speed 8 in a Bullet Blender (Next Advance, Inc., Averill Park, NY) and then treated with proteinase $\mathrm{K}$ $(20 \mathrm{mg} / \mathrm{mL})$ at $55^{\circ} \mathrm{C}$ for $1 \mathrm{~h}$. Ammonium acetate $(7.5 \mathrm{M})$ was then added for protein precipitation, followed by ethanol precipitation of the genomic DNA, and drying of the DNA pellet to remove any remaining ethanol. Pure genomic DNA was rehydrated in Millipore filtered and deionized water and stored at $4{ }^{\circ} \mathrm{C}$. A total of 96 microsatellite markers (Solignac et al. 2007) were screened for a previous study (Bourgeois et al. 2010b). Four were selected that showed high levels of polymorphism and were used for subsequent analyses. Primer sequences, GenBank accession numbers, and amplification conditions are listed in Table I. In addition to the forward and reverse primers, an additional primer (Univ) was used (Schuelke 2000). The Univ primer sequence is M13 (GAGTTTTCCCAGTCACGAC). This primer was modified with one of three fluorescent dyes (WellRed dyes; Integrated DNA Technologies, Coralville, IA) to facilitate pool-plexing of PCR products for fragment analysis. Pool-plexing is a method by which PCR products are mixed together and then analyzed simultaneously. The forward primer for each locus was modified (MF) at the $5^{\prime}$ end by the addition of the complementary sequence to the Univ primer. Amplification conditions were optimized on a Veriti Thermal Cycler ${ }^{\circledR}$ (Applied Biosystems, Foster City, CA) and were used for all subsequent reactions. The optimized amplification profile was for FAST PCR: $20 \mathrm{~s}$ at $95^{\circ} \mathrm{C}$, followed by 40 cycles of $1 \mathrm{~s}$ at $95^{\circ} \mathrm{C}$ and $20 \mathrm{~s}$ at $60^{\circ} \mathrm{C}$. Each $6.5-\mu \mathrm{L}$ reaction included 1.5 pmol of each primer (MF, R, and Univ), $2 \times$ GeneAmp $^{\circledR}$ Fast PCR Master Mix (Applied Biosystems, Foster City, CA), and template DNA (50-100 ng).

Amplification products were analyzed with a Beckman GeXP GenomeLab ${ }^{\circledR}$ Genetic Analyzer (Beckman Coulter, Inc., Fullerton, CA) and GenomeLab software (Beckman Coulter, Inc.). Four microliters of PCR product were mixed with Frag-400 size standards (Beckman Coulter, Inc.) and deionized

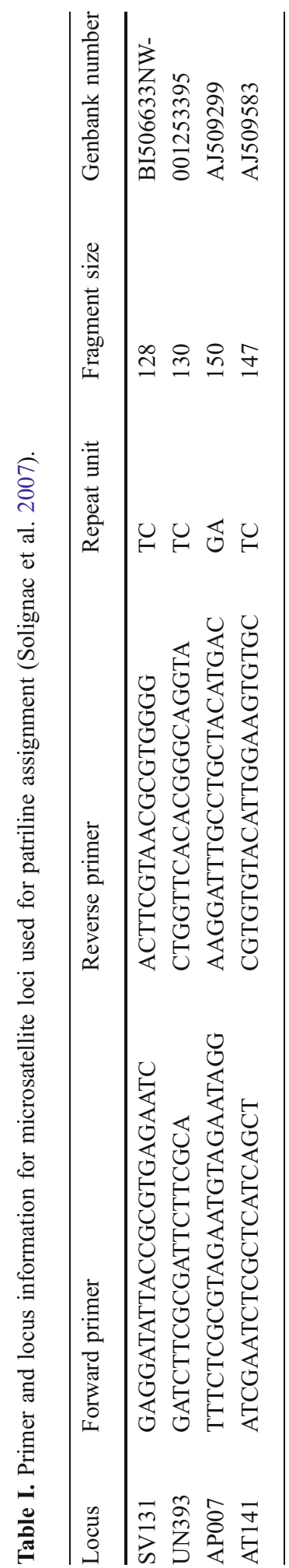


formamide. Samples were run according to the manufacturer's recommendations.

\subsubsection{N. ceranae detection and quantification}

Whole abdomens from each bee were homogenized with $100 \mathrm{mg} 1-\mathrm{mm}$ glass beads and $1 \mathrm{~mL}$ distilled water in a Bullet Blender (Next Advance, Inc., Averill Park, $\mathrm{NY}$ ). A $200-\mu \mathrm{L}$ aliquot of the homogenate was then transferred to a new tube and centrifuged at $14,000 \times \mathrm{g}$ for $2 \mathrm{~min}$. Whole abdomens were sampled to acquire a measure of total $N$. ceranae infestation (i.e., all life stages; vegetative, immature spore, and mature spore). The supernatant was removed and the pellet resuspended in $200 \mu \mathrm{L}$ of $0.3 \% \mathrm{H}_{2} \mathrm{O}_{2}$ and incubated at room temperature for $15 \mathrm{~min}$. Lysis buffer (100 mM Tris $\mathrm{pH} 8.0,10 \mathrm{mM}$ EDTA $\mathrm{pH} 8.0,1 \%$ SDS) and $100 \mathrm{mg} 1-\mathrm{mm}$ glass beads were then added to each sample and homogenized for $3 \mathrm{~min}$ at speed 8 in a Bullet Blender and then treated with $80 \mu \mathrm{L}$ proteinase $\mathrm{K}(10 \mathrm{mg} / \mathrm{mL})$ at $70^{\circ} \mathrm{C}$ for $10 \mathrm{~min}$. After proteinase $\mathrm{K}$ treatment, $7.5 \mathrm{M} \mathrm{NH}_{4} \mathrm{OAc}$ was added for protein precipitation, followed by isopropanol precipitation, $2 \times 70 \%$ EtOH washes, and lyophilization. Pure genomic DNA was rehydrated in Millipore filtered and deionized water and stored at $4{ }^{\circ} \mathrm{C}$.

Detection and quantification were performed on a StepOne ${ }^{\mathrm{TM}}$ Real-time PCR System (Applied Biosystems, Carlsbad, CA). Protocols for FAST PCR and reagent specifications followed those described by Bourgeois et al. (2010a). Modifications to the protocol were made by elimination of primers and probe reagents for $N$. apis and addition of distilled water to adjust the reaction volume to $12.5 \mu \mathrm{L}$. All other reagents and specifications remained the same. All samples were run in triplicate and were directly quantified by comparison to a standard curve of known levels of $N$. ceranae DNA copy number. Standards were generated from serial dilutions of a cloned PCR product of the target sequence from N. ceranae (Bourgeois et al. 2010a). Each set of reactions contained a no template control to detect the presence of potential contamination.

\subsection{Data analysis}

Patriline determination was generated from microsatellite genotypes of the four loci described in Table I using the software package COLONY (Wang
2004; Wang and Santure 2009; Jones and Wang 2010). Results from the real-time PCR assays (i.e., number of copies of the $N$. ceranae PCR product) were converted to numbers of individual $N$. ceranae genomes represented (as vegetative or spore form) per bee as described by Bourgeois et al. (2010a) and are expressed as Nosema/bee in whole numbers. Nosema "counts" were log transformed and subjected to analysis of variance to determine differences between patrilines, colonies, and lineages (GLM procedure using lineage, colony, and patriline as fixed effects, with patriline nested within colony: SAS v9.2, SAS Institute, Inc., Cary, NC). $P$ values were calculated for comparisons by day (using pdiff of LSMeans) when the GLM results were significant.

\section{RESULTS}

\subsection{Prescreening of Russian and Italian colonies (phase 1)}

Colony level measurements (expressed as Nosema/bee as estimated from 100 bees/colony) of $N$. ceranae in Russian colonies averaged $8 \times$ $10^{5}$ and ranged from 0 to $8 \times 10^{6}$ and in Italian colonies averaged $2 \times 10^{6}$ and ranged from 21 to $9 \times 10^{6}$ (Figure 1). Each of the five Russian colonies selected for individual level measurements had $N$. ceranae levels between $2 \times 10^{6}$ and $8 \times 10^{6}$. Each of the five Italian colonies selected had infestation levels between $2 \times 10^{6}$ and $9 \times 10^{6}$ Nosema/bee. The Russian and Italian colonies used in phase 2 did not differ in $N$. ceranae infestation levels $(P>0.05$; Figure 1) at the time of colony selection.

\section{2. $N$. ceranae levels in lineages and colonies used in patriline analysis (phase 2)}

Mean levels of $N$. ceranae infestation varied both by lineage [Italian: $9 \times 10^{6} \pm 4 \times 10^{6}$ (SE) Nosema/bee, Russian: $5 \times 10^{6} \pm 2 \times 10^{6}$ Nosemal bee, $P<0.0001]$ and among colonies within each lineage $(P<0.0001$ and $P<0.0001$, Italian and Russian, respectively; Table II). Among the five Russian and five Italian colonies chosen for detailed analysis in phase 2 of the study, mean 


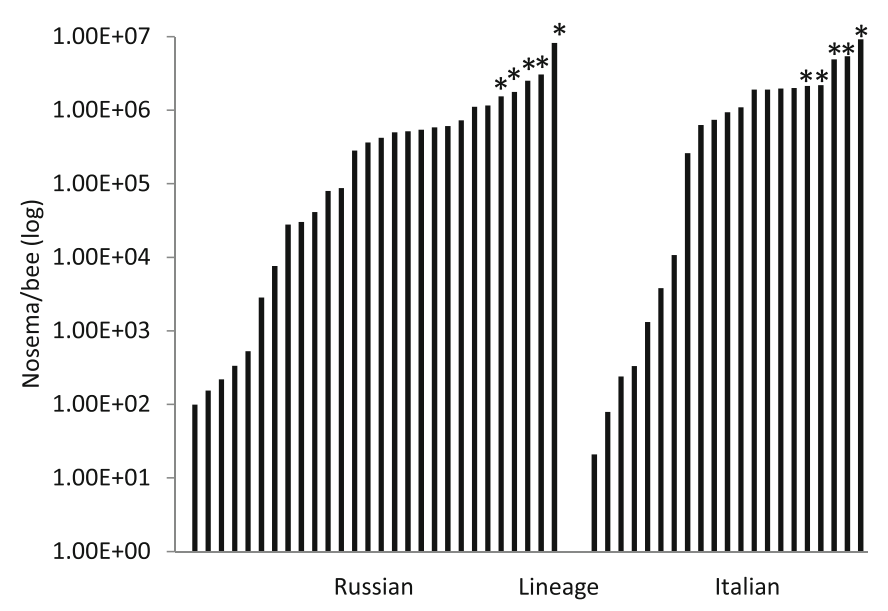

Figure 1. Number of N. ceranae/bee in colonies of Russian and Italian honey bees screened for use in patriline analysis. Values are generated from pooled samples of 100 bees/colony. Each bar represents the mean of a single colony sample. Data are plotted on a logarithmic scale. Colonies chosen for further testing in phase 2 are marked with an asterisk.

infestation levels ranged from $1 \times 10^{3}$ to $3 \times 10^{7}$ Nosema/bee. Although each of these colonies were the most highly infected in their apiary during phase 1 of the study, colony infestation levels varied widely during phase 2 (Table II, Figure 2).

Pairwise comparisons between each of the five phase 2 Russian colonies showed signifi- cant differentiation in mean $N$. ceranae levels with the exception of colony A. Relative to the other four Russian colonies, the variance among bees within colony A was large $\left(2 \times 10^{6} \pm 2 \times 10^{6}\right.$; mean \pm SEM; Table II, Figure 2).

Pairwise comparisons of the Italian colonies sampled in phase 2 of the study also showed

Table II. Summary data for infestation levels of $N$. ceranae and patriline numbers in colonies of Italian and Russian honey bees.

Nosema/bee

\begin{tabular}{|c|c|c|c|c|c|c|c|}
\hline Lineage type & Colony & Minimum & Maximum & Mean & SEM & $P$ value & \\
\hline Italian & All & 0 & $2 \times 10^{9}$ & $9 \times 10^{6}$ & $5 \times 10^{6}$ & $<0.0001$ & 66 \\
\hline Italian & A & 0 & $3 \times 10^{4}$ & $1 \times 10^{3}$ & $3 \times 10^{2}$ & & 9 \\
\hline Italian & B & 0 & $6 \times 10^{3}$ & $1 \times 10^{3}$ & $1 \times 10^{2}$ & & 10 \\
\hline Italian & $\mathrm{C}$ & 0 & $2 \times 10^{9}$ & $2 \times 10^{7}$ & $2 \times 10^{7}$ & & 18 \\
\hline Italian & $\mathrm{D}$ & 0 & $2 \times 10^{9}$ & $3 \times 10^{7}$ & $2 \times 10^{7}$ & & 12 \\
\hline Italian & $\mathrm{E}$ & 0 & $2 \times 10^{8}$ & $3 \times 10^{6}$ & $3 \times 10^{6}$ & & 17 \\
\hline Russian & All & 0 & $8 \times 10^{8}$ & $4 \times 10^{6}$ & $2 \times 10^{6}$ & $<0.0001$ & 58 \\
\hline Russian & $\mathrm{A}$ & 0 & $2 \times 10^{8}$ & $2 \times 10^{6}$ & $2 \times 10^{6}$ & & 18 \\
\hline Russian & $\mathrm{B}$ & 0 & $8 \times 10^{8}$ & $7 \times 10^{6}$ & $7 \times 10^{6}$ & & 14 \\
\hline Russian & $\mathrm{C}$ & 0 & $8 \times 10^{8}$ & $9 \times 10^{6}$ & $6 \times 10^{6}$ & & 7 \\
\hline Russian & $\mathrm{D}$ & 0 & $1 \times 10^{4}$ & $1 \times 10^{3}$ & $2 \times 10^{2}$ & & 9 \\
\hline Russian & $\mathrm{E}$ & 0 & $4 \times 10^{4}$ & $2 \times 10^{3}$ & $4 \times 10^{2}$ & & 10 \\
\hline
\end{tabular}

Number of

3)

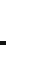



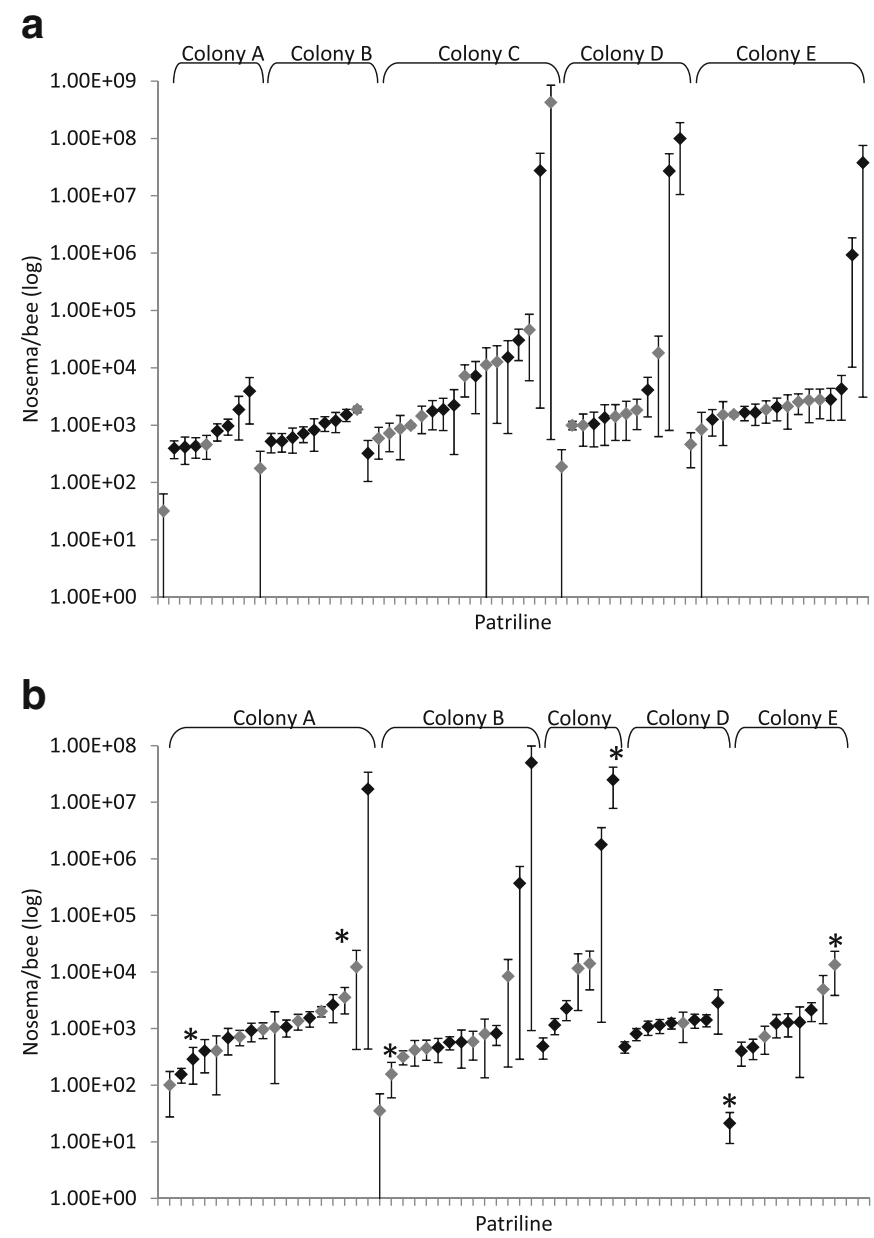

Figure 2. Patriline assignment and N. ceranae levels in five colonies of Italian (a) and Russian (b) honey bees. Each bar represents the mean and SEM of a single patriline. Patrilines with $n \geq$ median (Russian 7, Italian 6) are in black. All patrilines with $n<$ median are shaded in gray. An asterisk was placed over the patrilines that had the largest contribution to significant differentiation from other patrilines within each colony. Data are plotted on a logarithmic scale.

significant differentiation among colonies $(P<$ $0.0001)$. Italian colonies $\mathrm{A}$ and $\mathrm{B}$ had lower $N$. ceranae levels $\left(1 \times 10^{3} \pm 3 \times 10^{2}\right.$ and $1 \times 10^{3} \pm 1 \times$ $10^{2}$, respectively) when compared to the other Italian colonies $(P \leq 0.0001$; Table II).

\subsection{Patriline analysis of individual bees}

The number of patrilines in each colony ranged from 13 to 41 among the five Russian colonies and from 16 to 36 among the five Italian colonies. Patrilines with fewer than three individuals were removed from the analyses to reduce bias arising from low expected values. When these patrilines were removed, a large degree of variation among colonies for numbers of patrilines for both lineages of bees was still evident (Table II).

Within Russian colonies, infestation levels significantly differed among patrilines ( $P=0.02$; Figure 2). Colony D was the exception, due to low infestation levels overall $\left(1 \times 10^{3} \pm 2 \times 10^{2}\right.$; Table II), and nonsignificant variation among patrilines $(P>0.05$ for all pairwise comparisons of patrilines). Within the five Italian colonies, 
there was no significant differentiation among patrilines $(P=0.66$; Figure 2$)$

The proportion of bees infected (incidence) within each patriline differed between Russian and Italian colonies $(P<0.0001$; Russian$83.49 \pm 2.27 \%$, Italian- $66.4 \pm 2.36 \%$; Figure 3$)$. A comparison of incidence and abundance of $N$. ceranae infestation for each patriline revealed a positive correlation among Russian patrilines $\left(y=0.0251 x+1.2061 ; R^{2}=0.3476 ; P=0.007\right)$. No similar statistical relationship was evident among Italian colonies $(y=0.0092 x+3.0477$; $\left.R^{2}=0.1318, P=0.2563\right)$.

\section{DISCUSSION}

The results for the Russian honey bees are congruent with predictions derived from the parasite hypothesis for the evolution of polyandry in eusocial insect queens. The hypothesis predicts that an increase in genetic diversity within a colony will confer parasite resistance at the colony level (Tooby 1982; Hamilton 1987; Sherman et al. 1988; Schmid-Hempel 1995). While both lineages showed indications of patrilineal-based variation in levels of $N$. ceranae, only the Russian
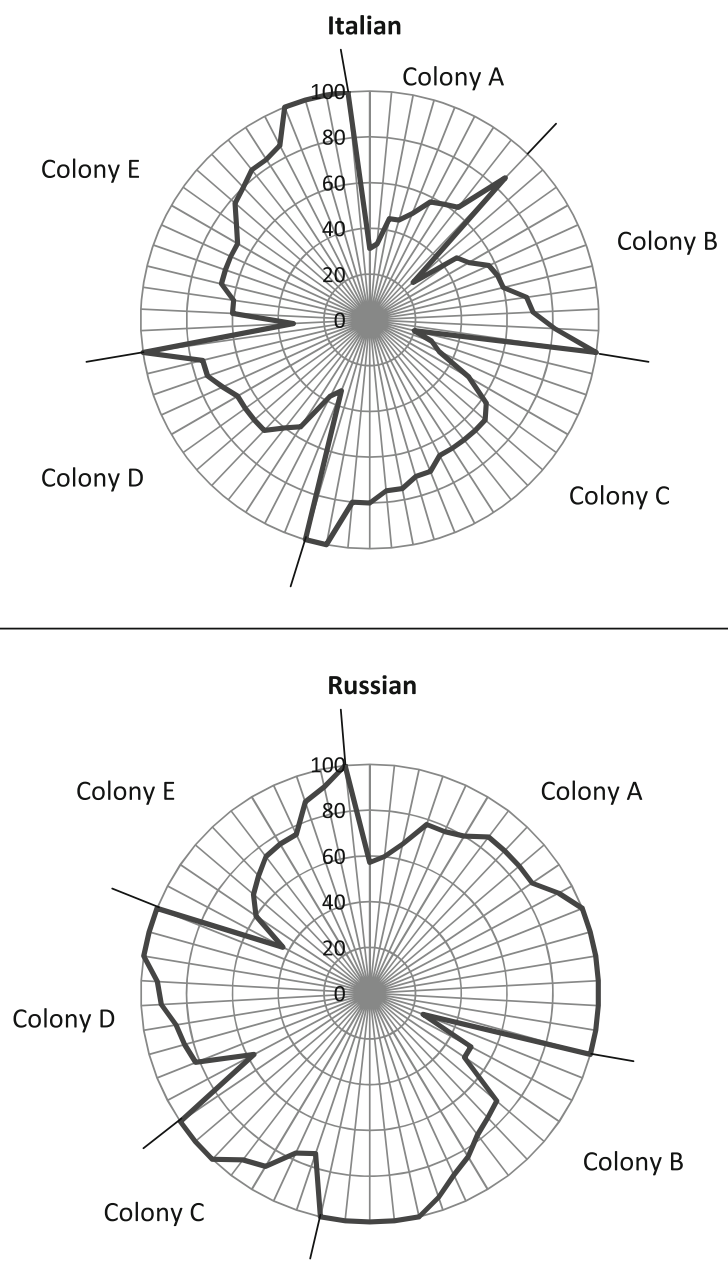

Figure 3. Plot of incidence of $N$. ceranae in Russian and Italian patrilines per colony. 
colonies demonstrated significant variation among patrilines.

Differentiation in $N$. ceranae levels among the lineages was evident in phase 2 despite selection of colonies with comparable infestation levels in the previous month (phase 1), although sampling months did differ seasonally. The cyclical patterns of $N$. ceranae infestations have not yet been well defined. Long-term studies are underway to elucidate more definitive patterns in the $N$. ceranae levels. While the Russian lineage had lower levels of $N$. ceranae, the incidence of infestation among individuals within each patriline was substantially higher and more consistent. High incidence but relatively low infestation level is indicative of a chronic infestation and may indicate the ability of many Russian honey bee patrilines to suppress acute infestations of $N$. ceranae.

The significant intracolonial genetic variance in both pathogen incidence and abundance found for Russian honey bees are consistent with findings with other organisms. Hughes and Boomsma (2004) showed that in the leaf cutter ant Acromyrmex echinatior, the incidence of a virulent fungal pathogen varied among patrilines. In $A$. mellifera the incidence of the bacterial pathogen Paenibacillus larvae also varied among patrilines (Palmer and Oldroyd 2003). Collectively, these studies strongly suggest that intracolonial genetic diversity enhances colony level disease resistance.

Artificial manipulation of patriline diversity has significant effects on colony level disease incidence. In naturally polyandrous honey bees, artificial reduction in intracolonial genetic diversity increases disease severity (Tarpy 2003; Tarpy and Seeley 2006; Seeley and Tarpy 2007). Remarkably, when artificial insemination was used to create polyandrous colonies in the naturally monandrous bumble bee (Bombus terrestris, Baer and Schmid-Hempel 1999), disease incidence was significantly reduced. Together, these studies show how colony level disease resistance is an emergent property of intracolonial genetic diversity. Our study extends these findings by showing how exposure to a pathogen selects for genetic diversity in the host.

Our study provides the first evidence for genetic variation in resistance to $N$. ceranae, but only in the Russian lineage. The source population for the Russian lineage was established from western European bees in far eastern Russia in the mid-1800s (Crane 1978). Thus the source population has been exposed to indigenous pathogens from the in that area, notably Varroa destructor and very likely $N$. ceranae. The first documented discovery of genetically based variance in resistance to $V$. destructor in A. mellifera was also in the parent population of the Russian lineage (Rinderer et al. 2001). In contrast, numerous breeding efforts to find genetic variance for resistance to $V$. destructor in Apis mellifera in Europe that was naive to the parasite have been unsuccessful (Buchler et al. 2010). It appears that for managed Russian honey bees, ca. 150 generations was sufficient for A. mellifera to respond to natural selection and develop genetic variance in resistance to parasites. The exceptionally high levels of recombination in A. mellifera (Beye et al. 2006) favor rapid evolution. Hamilton's (1980) hypothesis that sex evolved as a mechanism to thwart the evolution of virulent pathogens probably extends to the maintenance of extreme polyandry as well.

\section{ACKNOWLEDGMENTS}

We thank Lorraine Beaman, Tony Stelzer, Stephanie Johnson, Andrew Ellender, and Julian Escobar for their contributions to sample processing. We also thank Joshua Wales and Jeremy Wagnitz for sample collection. Mention of a trade name, proprietary product, or specific equipment does not constitute a guarantee or warranty by the USA Department of Agriculture and does not imply approval to the exclusion of other products that may be suitable.

Les profils de l'infestation d'Apis mellifera par Nosema ceranae soutiennent l'hypothèse de la relation hôte-parasite expliquant l'évolution d'une très forte polyandrie chez les insectes eusociaux. 
Polyandrie / lignée paternelle / Nosema ceranae / Apis mellifera / évolution de la polyandrie

\section{Das quantitative Muster der Infektionen mit Nosema ceranae bei Apis mellifera unterstützt die Parasiten- hypothese bezüglich der Evolution einer extremen Polyandrie bei eusozialen Insekten.}

Polyandrie / Patrilinien / Nosema ceranae / Apis mellifera / Evolution von Polyandrie

\section{REFERENCES}

Baer, B., Schmid-Hempel, P. (1999) Experimental variation in polyandry affects parasite loads and fitness in a bumble-bee. Nature 397, 151-154

Beye, M., Gattermeier, I., Hasselmann, M., Gempe, T., Schioett, M., Baines, J.F., Schlipalius, D., Mougel, F., Emore, C., Rueppell, O., Sirviö, A., Guzmán-Novoa, E., Hunt, G., Solignac, M., Page Jr., R.E. (2006) Exceptionally high levels of recombination across the honey bee genome. Gen. Res. 16, 1339-1344

Bourgeois, A.L., Rinderer, T.E., Beaman, L.D., Danka, R.G. (2010a) Genetic detection and quantification of Nosema apis and N. ceranae in the honey bee. J. Invertebr. Pathol. 103, 53-58

Bourgeois, A.L., Sheppard, W.S., Sylvester, H.A., Rinderer, T.E. (2010b) Genetic lineage identification of Russian honey bees. J. Econ. Entomol. 103, 917-924

Buchler, R., Berg, S., Le Conte, Y. (2010) Breeding for resistance to Varroa destructor in Europe. Apidologie 41, 393-408

Chen, Y., Evans, J.D., Smith, I.B., Pettis, J.S. (2008) Nosema ceranae is a long-present and wide-spread microsporidian infestation of the European honey bee (Apis mellifera) in the United States. J. Invertebr. Pathol. 97, 186-188

Crane, E. (1978) The Varroa mite. Bee World 59, 164-167

Ebert, D., Hamilton, W.D. (1996) Sex against virulence: The coevolution of parasitic diseases. Trends Ecol. Evol. 11, 79-82

Fries, I. (2010) Nosema ceranae in European honey bees (Apis mellifera). J. Invertebr. Pathol. 103, 73-79

Hamilton, W.D. (1980) Sex versus non-sex versus parasite. Oikos 35, 282-290

Hamilton, W.D. (1987) Kinship, recognition, disease and intelligence: constraints of social evolution. In: Ito, Y., Brown, J.L., Kikkawa, J. (eds.) Animal Societies: Theories and Facts, pp. 81-102. Japan Scientific Society Press, Tokyo

Hamilton, W.D., Axelrod, R., Tanese, R. (1990) Sexual reproduction as an adaptation to resist parasites (a review). Proc. Natl. Acad. Sci. 87, 3566-3573
Higes, M., Garcia-Palencia, P., Martin-Hernandez, R., Meana, A. (2007) Experimental infestation of Apis mellifera honeybees with Nosema ceranae (Microsporidia). J. Invertebr. Pathol. 94, 211-217

Higes, M., Martin-Hernandez, R., Botias, C., Bailón, E. G., González-Porto, A.V., Barrios, L., Del Nozal, M. J., Bernal, J.L., Jiménez, J.J., Palencia, P.G., Meana, A. (2008) How natural infestation by Nosema ceranae causes honeybee colony collapse. Environ. Microbiol. 10, 2659-2669

Hughes, W.H.O., Boomsma, J.J. (2004) Genetic diversity and disease resistance in leaf-cutting ant societies. Evolution 58, 1251-1260

Jaenike, J. (1978) On optimal oviposition behavior in phytophagous insects. Theoret. Pop. Biol. 14, 350-356

Jones, O.R., Wang, J. (2010) COLONY: a program for parentage and sibship inference from multilocus genotype data. Molec. Ecol. Resourc. 10, 551-555

Ladie, R.J. (1992) Parasites and sex: catching the Red Queen. Trends Ecol. Evol. 7, 405-408

Lively, C.M. (1987) Evidence from a New Zealand snail for maintenance of sex by parasitism. Nature 328, 519-521

Lively, C.M., Craddock, C., Vrijenhoek, R.C. (1990) Red queen hypothesis supported by parasitism in sexual and clonal fish. Nature 344, 864-866

Martin-Hernandez, R., Meana, A., Prieto, L., Salvador, A.M., Garrido-Bailon, E., Higes, M. (2007) Outcome of colonization of Apis mellifera by Nosema ceranae. Appl. Environ. Microbiol. 73, 6331-6338

Palmer, K.A., Oldroyd, B.P. (2000) Evolution of multiple mating in the genus Apis. Apidologie 31, 235-248

Palmer, K.A., Oldroyd, B.P. (2003) Evidence for intracolonial genetic variance in resistance to American foulbrood of honey bees (Apis mellifera): further support for the parasite/pathogen hypothesis for the evolution of polyandry. Naturwissenschaften $\mathbf{9 0}$, 265-268

Paxton, R.J., Klee, J., Korpela, S., Fries, I. (2007) Nosema ceranae has infected Apis mellifera in Europe since at least 1998 and may be more virulent than Nosema apis. Apidologie 38, 558-565

Rinderer, T.E., de Guzman, L.I., Delatte, G.T., Stelzer, J. A., Lancaster, V.A., Kuznetsov, V., Beaman, L., Watts, R., Harris, J.W. (2001) Resistance to the parasitic mite Varroa jacobsoni in honey bees from far-eastern Russia. Apidologie 32, 381-394

Schmid-Hempel, P. (1995) Parasites and social insects. Apidologie 26, 255-271

Schuelke, M. (2000) An economic method for the fluorescent labeling of PCR fragments. Nature Biotechnol. 18, 233-234

Seeley, T.D., Tarpy, D.R. (2007) Queen promiscuity lowers disease within honeybee colonies. Proc. Roy. Soc. B: Biol. Sci. 274, 67-72

Sherman, P.W., Seeley, T.D., Reeve, H.K. (1988) Parasites, pathogens and polyandry in social hymenoptera. Am. Nat. 131, 602-610 
Shykoff, J.A., Schmid-Hempel, P. (1991a) Genetic relatedness and eusociality: parasite-mediated selection on the genetic composition of groups. Behav. Ecol. Sociobiol. 28, 371-376

Shykoff, J.A., Schmid-Hempel, P. (1991b) Parasites and the advantage of genetic variability within social insect colonies. Proc. Roy. Soc. Lond. B: Biol. Sci. 243, 55-58

Solignac, M., Mougel, F., Vautrin, D., Monnerot, M., Cornuet, J.M. (2007) A third-generation microsatellite-based linkage map of the honey bee, Apis mellifera, and its comparison with the sequence-based physical map. Genome Biol. 8, R66. doi:10.1186/gb-2007-8-4-r66

Tarpy, D.R. (2003) Genetic diversity within honeybee colonies prevents severe infestations and promotes colony growth. Proc. Roy. Soc. Lond. B: Biol. Sci. 270, 99-103
Tarpy, D.R., Seeley, T.D. (2006) Lower disease infestations in honeybee (Apis mellifera) colonies headed by polyandrous vs monandrous queens. Naturwissenschaften 93, 195-199

Tooby, J. (1982) Pathogens, polymorphism, and the evolution of sex. J. Theor. Biol. 97, 557-576

van Baalen, M., Beekman, M. (2006) The costs and benefits of genetic heterogeneity in resistance against parasites in social insects. Am. Nat. 167, 568-577

van Valen, L. (1973) A new evolutionary law. Evol Theory 1, 1-30

Wang, J. (2004) Sibship reconstruction from genetic data with typing errors. Genetics 166, 1963-1979

Wang, J., Santure, A.W. (2009) Parentage and sibship inference from multilocus genotype data under polygamy. Genetics 181, 1579-1594 